\title{
LA INDUSTRIA DISCOGRÁFICA Y LOS CONSUMIDORES: ¿La música como bien comercial o gratuito?
}

\section{THE RECORDING INDUSTRY AND CONSUMERS:}

Music as a commercial or free property?

Fabián Eduardo Arango Archila *

\section{RESUMEN}

Este artículo describe el desarrollo de la industria discográfica internacional y el libre acceso a los contenidos fonográficos por parte de los consumidores, con base en la pregunta ¿por qué los melómanos perciben la música como un bien público, mientras las disqueras insisten en su concepción privada?

En este sentido, el objetivo principal del texto es analizar la concepción del fonograma desde la perspectiva comercial de las disqueras y el uso público por parte de los melómanos, a medida que un mundo offline daba paso a la digitalización de la música a finales de los noventa. De manera que se estudiarán el modelo de negocio tradicional de comercialización de formatos físicos, -como los discos compactos-, los sistemas $\mathrm{P} 2 \mathrm{P}$ y las plataformas de streaming.

Con base en lo anterior, también se abordaron otros objetivos secundarios que son: describir el impacto de la era digital en casas discográficas, distribuidoras online y consumidores; identificar las razones y motivos que han llevado a los usuarios a considerar la música como un bien libre y anti-comercial; y estudiar el contexto de las disqueras como defensoras de los derechos de autor y la propiedad intelectual, como base de sus negocios.

Palabras clave: industria discográfica, consumidor de música, sistemas P2P, servicios de streaming, iTunes.

\section{SUMMARY}

This article describes the development of the international record industry and the free access to the phonographic contents by the consumers, with based on this question: why internet and its users have transformed music into a public good, while the labels insist on its private conception?

Thus, the main objective of this article is to analyze the phonogram conception from the commercial perspective (labels) and from the public use (music lovers), since an offline world changed to an online planet, where took place the music digitalization at the end of the nineties. In this sense, this research will study the traditional business model and its sales of compact discs and other physic formats, the Peer to Peer (P2P) systems, and streaming platforms.

Based on the main purpose, the secondary objectives will be: to describe the impact of the digital era on labels, online music stores, streaming services, and consumers; to identify the main reasons and motives that have made the users to consider music as a public good since an anti-commercial point of view; and to study the majors and indies context and their defense of copyrights and intellectual property as a root of their business.

Keywords: record industry, music consumer, P2P systems, streaming services, iTunes. 
Introducción

Este artículo [1] muestra la evolución de la industria discográfica internacional y su constante defensa de los derechos de autor, como base de su modelo de negocio: desde la venta de formatos físicos, hasta la utilización de internet para comercializar fonogramas en mp3, y a través de servicios de streaming o en la nube. Al mismo tiempo, describe, desde finales del siglo XX hasta la actualidad, el cambio de mentalidad del melómano, quien pasó de percibir la música como un bien privado [2] y costoso, concediéndole un uso libre y gratuito, cuando el ciberespacio hizo posible la democratización de miles de canciones.

De esta manera, la hipótesis central de la investigación cuyo producto es este artículo, fue afirmar que, en la actualidad, los usuarios han obtenido un triunfo en su lucha por democratizar la música, al lograr acceder a los fonogramas a precios más accesibles, a causa del auge de internet, mientras que las disqueras también se han anotado una victoria al lograr que el público consuma los contenidos musicales de manera legal, a través de los servicios de streaming, aunque sin generar los altos ingresos de los noventa, cuando se vendían discos compactos.

La revisión de las dos miradas diferentes sobre el fonograma, que tuvieron tanto los melómanos como las disqueras, hace precisamente que el aporte de este trabajo sea la exposición combinada del uso público y privado de la música [3], ya que la mayoría de la literatura se enfoca en apoyar a los usuarios en su defensa de la gratuidad de los fonogramas, o en tomar partido a favor de la industria discográfica en su derecho de lucrarse con su negocio de comercialización de álbumes y canciones.

Como parte del planteamiento del problema, la investigación trató de resolver la pregunta: ¿por qué los melómanos perciben la música como un bien público, mientras las disqueras insisten en su concepción privada? Con base en este cuestionamiento, se pueden formular otros: ¿cuál fue el papel de Napster en los nuevos modelos de negocio?, ¿qué victorias obtuvieron las empresas discográficas y qué triunfos lograron los consumidores en su lucha por convertir el fonograma en un producto lucrativo o gratuito? y ¿cuál fue la influencia de internet en la mentalidad de los usuarios y de los sellos?

Estas preguntas han estado guiadas desde un objetivo principal, que ha sido el hilo conductor del texto y que es el siguiente: analizar la concepción del fonograma desde la perspectiva comercial de las disqueras y el uso público por parte de los melómanos, a medida que el mundo offline daba paso a la digitalización de la música a finales de los noventa.

De allí se derivan tres objetivos secundarios: A) Describir el impacto de la era digital en casas discográficas, distribuidoras online y consumidores; B) Estudiar el contexto de las disqueras como defensoras de los derechos de autor y la propiedad intelectual como base de sus negocios C) Identificar las razones y motivos que han llevado a los usuarios a considerar la música como un bien libre, antiindustrial y anti-comercial.

Finalmente, este trabajo estará dividido en dos capítulos que obedecen a una cronología en el tiempo. El primero, analizará el modelo de negocio tradicional de la industria discográfica de finales del siglo XX, hasta la clausura de Napster en 2001, época dorada de las disqueras. El segundo, describirá los años transcurridos del nuevo milenio, periodo caracterizado por la creación de iTunes, la aparición y cierre de servicios Peer to Peer (P2P) ilegales y la llegada de las plataformas de streaming, como Spotify.

1. Del modelo tradicional a la desaparición de Napster

A lo largo de la historia de la industria discográfica, la música ha sido concebida desde dos perspectivas diferentes. El punto de vista de las disqueras y artistas, quienes se han encargado de producir, distribuir y promocionar los fonogramas, y su objetivo es productivo, comercial y de uso privado; mientras que la concepción de los consumidores, aquellos melómanos que escuchan miles de canciones y discos diariamente, piensan que oír los álbumes o sencillos debe tener un carácter cultural, libre y hasta gratuito, donde los valores capitalistas del lucro y la competición (Fuch, 2008, 301) no tienen espacio en una cultura pirata que tiene su espina dorsal en el dominio público (Mason, 2008, 39).

En un principio, en el siglo XVIII, el copyright [4] se creó como un mecanismo para balancear los intereses públicos y privados, a través de la eliminación de los monopolios, y así motivar los trabajos creativos (Bishop, 2005, 453). Sin embargo, desde 1950, con el advenimiento de la tecnología y bajo la óptica de la guerra fría [5], (época en que los Estados Unidos defendieron a ultranza los valores capitalistas), los derechos de autor beneficiaron cada vez más a las disqueras majors [6], a costa del bien general de los consumidores melómanos, de manera que el sector 
musical, como toda industria cultural, sumida en una economía de mercado, fue convirtiéndose en una serie de empresas con ánimo de lucro (Garofalo, 1999, 318).

Esta rivalidad entre la concepción de la música como bien público o privado, gratuito o lucrativo y comercial o cultural se ha acentuado desde 1999, cuando internet hizo evidente que el modelo tradicional de vender discos estaba amenazado por el intercambio de canciones que se podía hacer gratuitamente a través del ciberespacio, y que dejaba desactualizadas las leyes de los derechos de autor, normativas que han protegido legalmente a compositores, artistas y empresas que producen los fonogramas.

Sin embargo, la Internet no ha sido la única amenaza para la supervivencia de la industria discográfica. En palabras de Kostas Kasaras, "in the past several technological developments have already challenged the music industry's status quo in similar ways" (2002). A lo largo del siglo $\mathrm{XX}$, las disqueras temieron perder el control privado de la música y, por lo tanto, sus ganancias económicas, básicamente por la radio y los casetes regrabables (Palmeiro, 2004, 37), tecnologías que permitieron extender masivamente la escucha pública y gratuita de canciones, a través de miles de emisoras desde los años de 1920 hasta la actualidad y que, más tarde, en 1980, facilitaron la grabación programas de las estaciones de FM y AM e incluso, de otros fonogramas por medio de las grabadoras y estéreos con doble casetera.

No obstante, en ambas ocasiones, la industria discográfica salió victoriosa en su lucha contra el uso público y libre de la música. Si bien en 1920, las disqueras vieron como rival a la radio para el negocio de la comercialización de sus discos (Tschmuck, 2003, 131; Bett \& Taran, 2004, $35)$, en las siguientes décadas se fueron dando cuenta que era imposible competir contra las emisoras, y convirtieron esa amenaza en una oportunidad para promocionar los mejores álbumes $y$ éxitos del momento. Más tarde, en las décadas del setenta, ochenta y noventa, época en que la venta de fonogramas fue creciendo rápidamente, los consumidores entendieron que pese a poder acceder gratuitamente a las estaciones radiales, si querían tener en casa un producto de valor agregado, debían pagar por el trabajo adicional que implicaba adquirir un vinilo, un casete o un $C D$ (Ministerio de Cultura, 2003, 100).

Más tarde, entre mediados de la década del sesenta hasta principios de los ochentas, la industria discográfica vio amenazada su hegemonía por la comercialización de casetes, los cuales habían sido vistos por las disqueras como un reemplazo para los conciertos en vivo (Bett \& Taran, 2004, 35) y unos productos baratos y fáciles de duplicar por parte de los consumidores (Katz, 2009, 15), además de la autonomía con que los usuarios grababan sus propios repertorios para regalársela a sus amigos (Yudice, $2007,36,47)$, y sin que las empresas productoras y dueñas de los derechos de autor recibieran ninguna compensación por este intercambio de música.

El fin de las preocupaciones de la industria discográfica respecto a este tipo de piratería finalizó en 1982, cuando los discos compactos empezaron a comercializarse, trayendo grandes ventajas como la mejora en la nitidez del sonido y su dificultad para duplicarse en equipos domésticos. Pero el logro principal de las majors y los artistas, que impidió que a los fonogramas se les continuara dando un uso público es descrito por Ana María Ochoa: "a diferencia del producto copiado en casete, el producto copiado en $C D$ es exactamente igual en calidad sonora al original" $(2003,21)$.

En 1982, el modelo tradicional de negocio de la industria discográfica continuó apostándole a la venta en serie de fonogramas (cada vez más discos compactos y menos casetes), cuyos contenidos musicales habían sido previamente escogidos en un proceso de selección riguroso, donde los artistas y bandas enviaban demos de sus canciones, para lograr contratos con las disqueras y así financiar la producción, los videos, el mercadeo y la distribución.

Esto significó para las disqueras una victoria total en su lucha contra la piratería casera y las ventas ilegales de álbumes, porque garantizaban sus ingresos a través de la producción en serie, y por medio del interés de los consumidores de adquirir CDs, productos novedosos por su sonido digital, que únicamente estaban siendo editados por las casas discográficas, ya que aún la tecnología no inventaba aparatos para duplicar discos compactos. 
Como resultado de esta situación, en Estados Unidos hubo un ascenso continuo en la comercialización de fonogramas, durante casi dos décadas [7], hasta que en 1999, con una cifra de más de 14.000 millones de dólares, los ingresos empezaron a disminuir (Stanislas, Faulk \& Goodrich, 2013, 166).

El periodo de 1982-1999 fue fructífero para las majors porque pudieron explotar al máximo los dividendos de la comercialización de álbumes y sencillos, manteniendo durante las décadas de los ochentas y noventas un control privado, casi absoluto sobre los consumidores, quienes aun sabiendo que podían duplicar fácilmente sus casetes, prefirieron adquirir discos compactos. Sobre el particular, George Yudice afirma: "millones de aficionados a la música no sólo empezaron a comprar CDs, sino que además fueron reemplazando su colección de música hasta bien entrada la década de 1990" $(2007,49)$.

Este éxito financiero de la industria discográfica, en lo referido a la obtención máxima de utilidades a través de la comercialización de discos, fue también posible gracias a la actualización de las leyes en Europa y en Estados Unidos durante los noventa, época cuando las majors tuvieron un triunfo legislativo con la ampliación de las licencias y los derechos de autor [8] para los fonogramas, evitando que pasaran a ser de dominio público (Bishop, 2005, 443-444; Garofalo, 1999, 348) de manera que las disqueras podían legalmente continuar dándole a la música un carácter lucrativo, haciéndole ver a los consumidores que debían pagar por un producto que era difícil de adquirir a través de sus amigos o en el mercado informal.

Como resultado de todo lo anterior, las disqueras pudieron controlar el comercio fonográfico internacional hasta finales de la década del noventa. En palabras de Juana López: "en la industria tradicional, los contenidos relacionados con la música fueron concebidos por la industria discográfica como bienes privados, lo que permitía regular su uso" (2014, 54). Fue tal el auge de este modelo de negocio en la comercialización de álbumes, que el mismo Mick Jagger, líder de la banda Rolling Stones y además economista, declaró alguna vez que únicamente durante el periodo de 1970 a 1997, los artistas recibieron ganancias significativas por concepto de ventas de discos u otro tipo de grabaciones (citado por Arias \& Ellis, 2013, 124).

Entretanto, los melómanos parecían ser los más afectados con la forma de comercializar la música por parte de la industria discográfica. Mientras que para las disqueras, la venta física de fonogramas era rentable y les hacía mantener el control del negocio, para el público con menores ingresos la situación era excluyente y poco democrática. En palabras de Juan Carlos Valencia: "el modelo de negocios tradicional se montó en los altos precios y descuidó a la mayor parte de los consumidores" (2007).

Gran parte de estos consumidores musicales se encontraba en países subdesarrollados, donde la pobreza, el bajo ingreso y la desigualdad hacían que fuera difícil adquirir un disco compacto, puesto que éste costaba lo mismo que en Estados Unidos, con la diferencia de que las naciones más pobres tenían una renta per cápita mucho menor [9] que las del imperio del norte. Con el ejemplo del hemisferio americano [10], George Yudice ejemplifica que "debería ser evidente que el modelo de negocio que buscan defender la IFPI y las majors no tiene sentido para la gran mayoría latinoamericana" [11] $(2007,79)$.

No obstante, a finales de los noventa, la industria discográfica nuevamente vio amenazada su existencia, y la democratización de la música para los consumidores se hizo posible debido a la llegada de los quemadores; unos aparatos integrados a los computadores, que grababan discos compactos y que si bien eran costosos para la época, posibilitaron la copia de CDs, manteniendo la misma calidad del formato original (Civano, 2003, 3-4). Desde ese momento, las majors dejaron de tener el control total sobre el negocio musical, y las empresas de tecnología y multimedia pasaron a la vanguardia.

Como consecuencia, "las productoras discográficas experimentaron un desplome en las ventas debido a la llegada de los quemadores incorporados a los PCs (Arango, 2015, 115). Esto sumado a que los CDs en blanco empezaron a ser comercializados libremente, y "para el año 2000, la gente estaba grabando en discos vírgenes con un total frenesi" (Isaacson, 2011, 481), se sentaron las bases para que los consumidores empezaran a concebir un mejor precio de los fonogramas, que ahora podían adquirir en cada esquina de las grandes ciudades o a través de un amigo que tuviera un computador con equipo de copiado; todo ello por fuera de la órbita de influencia de las disqueras.

El comercio ilícito de discos compactos no originales se triplicó en todo el mundo entre 2000 y 2001 (Ochoa, 2003, 77), especialmente, en las regiones menos desarrollados como fue el caso de 
Latinoamérica, donde "la mayoría de oyentes de música en los países en vías de desarrollo compra CD piratas porque no puede pagar los 15 dólares que se cobran en el mercado legal" (Yudice, 2007, 72). De esta forma, se ha producido una liberalización en los contenidos musicales a costa de las disqueras, al tiempo que los consumidores han logrado un mejor acceso a los fonogramas que, ahora, están fuera del control de la industria legal.

Ante esta dramática situación, las majors, la RIAA (Record Industry Association of America) y la IFPI (International Federation of the Phonographic Industry), se aferraron a defender sus tradicionales modelos de negocio, donde debía prevalecer el licenciamiento extremo del derecho de autor como base de su rentabilidad, aun sin tener en cuenta que los avances de la multimedia y los deseos de los consumidores auspiciaban la democratización y el acceso a la música. Las disqueras, dispuestas a no perder más ingresos y a mantener el control privado de la venta de álbumes y sencillos, recurrieron a un software especial que impedía grabar un disco compacto. Sobre el particular, Juan Carlos Monroy dice: "en materia de medidas tecnológicas de protección la industria fonográfica a nivel internacional se ha valido de varios intentos por sacar al mercado sus productos en soportes de CD o DVD acompañados de dispositivos que impiden su copia o reproducción" $(2006,37)$.

No obstante, los expertos en tecnología se las ingeniaron para desbloquear los discos compactos, [12] con mecanismos de seguridad anti copiado (Monroy, 2006, 37) y así, fracasaron los esfuerzos de la industria discográfica por frenar el intercambio de CDs que no estuvieran bajo su tutela, lo cual se convirtió en un logro más para el consumidor y su lucha por la democratización de la música. [13]

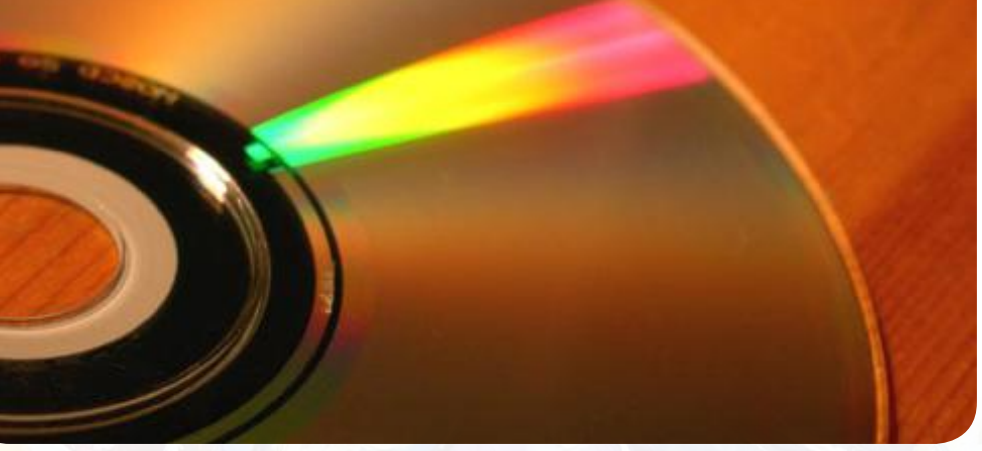

También los melómanos obtuvieron otro triunfo en la liberalización de la música cuando en 1998, la empresa Diamond Multimedia System creó RIO [14], el primer dispositivo portátil que almacenaba archivos de MP3. Pero como el aparato carecía de mecanismos de anti copia, la RIAA demandó a sus fabricantes por supuestamente, facilitar la piratería a través del intercambio de archivos (Das, 2000, 728), y así violar la ley del Audio Home Recording Act. Sin embargo, a principios del nuevo milenio, los tribunales desestimaron las denuncias de la industria discográfica [15], defendiendo la causa de la compañía acusada que el reproductor no se había sido hecho con el fin de duplicar fonogramas, sino de almacenarlos (Garofalo, 1999, 350). De esta manera, la portabilidad de canciones comprimidas, ahora legal, hizo que los consumidores se anotaran otra victoria en su lucha por concebir como de uso público a los álbumes y sencillos, apoyados esta vez por la justicia estadounidense y por los negocios de tecnología.

Adicionalmente, la industria discográfica tuvo que enfrentar una amenaza peor que la radio (1920), la piratería de casetes (1965-1998 [16]) o la llegada de los quemadores (1999). A finales de la década del noventa, el mayor enemigo para la IFPI, la RIAA y las majors fue el ciberespacio, porque en la web se empezaron a compartir gratuitamente archivos comprimidos de música, los cuales convertían al fonograma en un producto de uso público. Al respecto, Jim Rogers menciona: "the copying and sharing of music prior to the internet and MP3 technologies was never significant enough to stunt the growth of the record industry" $(2013,49)$.

En particular, el mayor rival en toda la historia de la industria discográfica fue Naspter; una plataforma en internet, creada en junio de 1999 por Shawn Fanning, quien hizo de su portal virtual un sistema P2P. Es decir, un servicio gratuito de distribución de música en archivos MP3 [17], formato que comprimía un disco compacto tradicional al punto de poder ser accesible digitalmente, lo cual motivó inicialmente a cientos de estudiantes a descargar sus canciones favoritas desde los campus universitarios, porque eran los lugares donde había banda ancha de gran velocidad (Kask, 2011, 106; Wade, 2004, 13).

La industria discográfica no tardó en protestar por la invención de Shawn Fanning puesto que, según ellos, estaba facilitando la tecnología para hacer que miles de usuarios compartieran canciones y álbumes completos en línea, sin pagar los copyright $y$, por tanto, dejar a las majors fuera del negocio de la comercialización de fonogramas. El primer logro de las disqueras fue a partir de febrero de 2000, cuando la Universidad de San Diego, seguida de otras 100 
instituciones de educación superior en Estados Unidos prohibieron el uso de Naspter en sus campus (citado de Menn por Bishop, 2005, 460-1).

También, algunos artistas se opusieron a la plataforma de Fanning, ya que consideraron que únicamente los creadores y aquellos que financiaran su grabación tenían derecho sobre sus obras y, por tanto, su explotación comercial debía continuar siendo de carácter privado, es decir, estar a cargo de las disqueras. Fue así como a un integrante de la legendaria agrupación Metallica, se le encargó la cruzada contra la piratería digital: "a Lars Ulrich, baterista de la banda, lo nombraron portavoz de la batalla contra Napster" (Hernández, 2011, 28).

Por otra parte, la perspectiva del melómano fue diferente, en cuanto concibió la llegada de Napster como una plataforma tecnológica que democratizaba los fonogramas, y permitía su uso público y gratuito. Esta visión de los consumidores fue apoyada, en gran parte, por la academia desde donde, por ejemplo, el profesor Enrique Dan declaró: "Shawn Fanning liberó a la música de la tiranía de su soporte físico, y la independizó del concepto conocido como "coste por copia»" (2006, 34). A partir de 1999, cientos de discos y sencillos estaban al alcance de miles de usuarios alrededor del mundo, sin importar distancias o tiempos. El acceso libre y la descarga de canciones y álbumes vía digital fue tan popular, que los motores de búsqueda reportaron que el término "MP3" fue la segunda palabra más buscada en sus servidores, solo después del término "sexo" hacia finales de los noventa (Garofalo, 1999, 349).

Esta situación no podía ser permitida por las disqueras, quienes demandaron a Napster: "fue desmembrado por las discográficas luego de una larga batalla legal que lo encontró copartícipe del delito por operar desde un servidor central (Civano, 2003, 5). A finales de 2001, la plataforma cerró sus servicios y pronto se convirtió en un portal asociado a las majors, quienes se anotaron un triunfo con la desaparición de este sistema P2P gratuito porque, ante la opinión pública, transmitieron que finalmente la justicia se hace para preservar los intereses privados. No obstante, la RIAA calculó 300 millones de dólares (Pikas \& Lymburner, 2011,140 ) por pérdidas a la industria musical a causa de la invención ilegal de Fanning, distribuidora online que alcanzó a contar con 50 millones de usuarios, en menos de tres años (Buquet, 2002, 94).

A pesar de que la industria discográfica obtuvo una victoria con el cierre de Napster,[18] nunca podría recuperar su época dorada de los ochenta y noventa, periodo cuando los usuarios reemplazaron sus colecciones de casetes por discos compactos, y el modelo de negocio offline parecía funcionar ante la poca expansión de la Internet. A finales de los noventas, las disqueras cedieron poder en su defensa extrema del derecho de autor, y en su interés por controlar la música, negándole el acceso a todo aquel que no estuviera en capacidad de pagar por ella.

Los impases de las disqueras no sólo fueron consecuencia de la llegada de los quemadores, los discos compactos vírgenes y los sistemas $\mathrm{P} 2 \mathrm{P}$, también se debió a una razón relacionada con Napster, que si bien su cierre significó una victoria efímera para las majors, la aparición de esta plataforma había sentado las bases para que los consumidores reclamaran un cambio en el modelo de negocio tradicional, donde internet ejerciera un papel más democratizador de la música, aspecto en el que, obviamente, los sellos discográficos no estaban interesados en ceder. Sobre el particular, Juana López afirma: "los compradores habituales ya no estaban dispuestos a asumir los altos costos finales de los fonogramas, en un entorno donde la tecnología digital les concedía potestad para disponer y transformar la información a su feliz arbitrio. $(2014,53)$

Como consecuencia de Napster y en detrimento de la industria discográfica, a partir de 1999, "muchas personas con acceso a Internet dejaron de comprar discos, pues podían obtener una gran cantidad de música gratuitamente y escoger por separado las canciones de su gusto, sin estar condicionados por la compra de todo el disco" (Weber, 2010, 93-94). Esto significó una democratización de los fonogramas, lo cual creó las raíces para la flexibilización de los precios en cuanto, en el futuro,

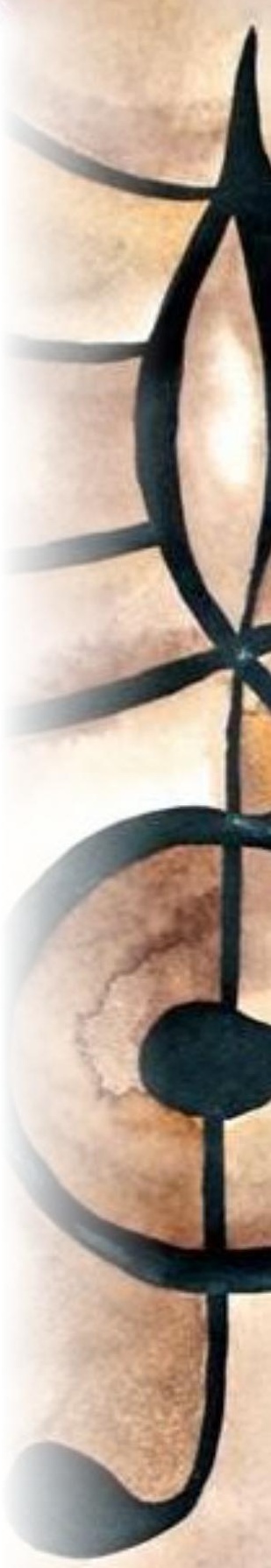


iTunes cobraría por canción -no necesariamente por álbum-, ahorrándole dinero al melómano, quien también cambió su mentalidad de consumo.

Esta sociología del consumidor empezó desde mediados de los años noventa, cuando el ciberespacio hizo que los usuarios pudieran acceder "gratuitamente a contenidos como las noticias y cada vez más a la música" (Portal, Sánchez \& Torres, 2013, 190), así como también a servicios libres de email, almacenaje de datos y software gratuito, lo que acostumbró a los internautas a que lo digital no tenía costo, "as a result, "free" became a well-accepted norm in the world of the Internet" (Ching Lin \& Others, 2013, 321). Pese a que las organizaciones vieron la web como una oportunidad para comercializar sus productos (Kleiner, 2010, 15), las generaciones de melómanos del nuevo milenio concibieron el entorno online como un espacio donde no se respetan los derechos de autor ni mucho menos pagar por los fonogramas [19] (Monroy, 2006, 44), lo que constituyó un gran reto para la industria discográfica en el futuro, tras el cierre de Napster.

\section{De los servicios $p 2 p$ a las plataformas de streaming}

La popularidad de la Internet en el nuevo milenio cuestionó los antiguos modelos de negocio de la industria discográfica, que concebían al fonograma como un bien mercantil, privado y lucrativo, que, a través de la venta de copias físicas en tiendas offline, generaba altos dividendos debido al control que las disqueras ejercían desde el precio de los discos compactos hasta su edición y distribución. En palabras de Glenn Hardaker y Gary Graham "Controlling the content was simply the way that the music industry has been paid in the past" $(2003,18)$.

Desde el año 2000, quedó comprobado que el ciberespacio democratizó cientos de sencillos y álbumes al facilitar, por medio de la plataforma de Napster, que los usuarios compartieran libre y gratuitamente infinidad de canciones en MP3, y así se permitiera que "el libre acceso a la información -impulsado por el desarrollo de las comunicaciones en red- desvirtu[ara] el concepto de exclusividad en los procesos de producción, comercialización y promoción de contenidos musicales" (López, 2014, 55).
La llegada del nuevo milenio planteó una nueva lógica en el consumo de música, ya que la Internet y las tecnologías de la información y la comunicación (TIC) transformaron la visión tanto de los consumidores como de las majors. De los usuarios, puesto que "suddenly, consumers could get the music that they wanted freely, quickly, and in a format that enabled them to copy each track over and over and over again" (Papagiannidis, 2007, 27), y de las disqueras porque "the industry intrinsically feared the internet for its philosophy of open source, sharing, freedoms, and common space" (Bishop, 2005, 458).

En suma, el advenimiento del año 2000 fue fundamental para la industria discográfica, al transformar la manera de dimensionar la Internet, que pasó de ser un medio de comunicación en los noventa, a convertirse en una plataforma que posibilitó el intercambio electrónico de fonogramas. Como dice Cristian Ballen, "este nuevo escenario que plantea la era digital muestra una liberalización de la música. Los contenidos se pueden adquirir de manera libre, se pueden compartir de igual modo y ahora se pueden producir bajo otro tipo de condiciones" (2011, 14).

Esta nueva concepción de la Internet, como plataforma capaz de almacenar archivos de MP3, motivó a los usuarios a crear sistemas P2P como Audiogalaxy, Morpheus, Grooveshark [20] y Kazaa, portales gratuitos de descarga de música en la web, inspirados en la experiencia Napster (Civano, 2003, 5; Hernández, 2011, 29), y auspiciados por la banda ancha, un tipo de conexión que aumentó la velocidad de navegación en el ciberespacio y cuyo servicio se incrementó en todo el mundo a partir del año 2000.

Además, esta nueva relación de la Internet y la música fue favorecida por el cambio de mentalidad del melómano, quien desde el nuevo milenio, ha dimensionado la web como un espacio virtual libre, público y anti mercantil, donde las majors tienen menos control que antes. En palabras de Juana López: "Se trata en realidad de una nueva lógica de acceso a la información, como parte de la apertura tecnológica que cuestiona el principio restrictivo de exclusividad" $(2014,58)$.

Por otra parte, también las disqueras se inspiraron en la experiencia de Napster para crear sus propios servicios de venta de música, y así mantener su status quo en la comercialización de canciones y álbumes, y recuperar el control privado de los fonogramas, con el fin de volver a obtener los altos dividendos 
de los noventa [21]. A principios del nuevo milenio, las majors estuvieron reacias a conceder licencias para crear plataformas $\mathrm{P} 2 \mathrm{P}$, porque aún defendían el modelo de negocio tradicional offline, pero pronto cedieron para combatir la piratería (Renard, Faulk \& Goodrich, 2013, 152).

De esta forma, en 2002, las majors crearon dos servicios P2P que, aunque fueron un fracaso desde el punto de vista económico y tecnológico [22], dejaron en claro a la opinión pública dos cosas: que se debía pagar por descargar música en la Internet y que las cinco disqueras principales continuaban en el negocio de los fonogramas. Por un lado, Warner, EMI y BMG crearon RealNetworks y, por el otro, Universal y Sony lanzaron al mercado Pressplay (Buquet, 2002, 96; Isaacson, 2011, 497-498). Sin embargo, ninguna de las dos plataformas logró el éxito comercial esperado por la competencia entre ellas y hasta quedó la impresión en la opinión pública que ni siquiera los sellos discográficos podían ponerse de acuerdo en sus mismos objetivos lucrativos, mientras que los sistemas ilegales auspiciaban la cooperación entre usuarios para acumular cada vez más pistas en MP3.

Ante este panorama, las disqueras se concientizaron de que la mejor manera de combatir los contenidos libres en Internet y así motivar a los usuarios a pagar por los fonogramas, era a través de la creación de mejores plataformas $\mathrm{P} 2 \mathrm{P}$, con un acceso simple a catálogos y con gran disponibilidad de canciones (D Sandulli \& Martin, 2004, 35). Esta idea emprendedora fue llevada finalmente a cabo en Estados Unidos, en 2001, por la compañía Apple, creadora de iTunes, una distribuidora de música online que convertiría el uso del MP3 de una concepción pública a una privada, al cobrársele a los consumidores $\$ 0,99$ centavos de dólar por pista. Steve Jobs, creador de la empresa de la manzana, afirmó: "la mejor forma de detener la piratería -la única forma, de hecho- consistía en ofrecer una alternativa más atractiva que aquellos absurdos servicios que estaban preparando las discográficas" (citado por Isaacson, 2011, 498).

La plataforma inicial de iTunes ofreció los catálogos de las cinco majors (BMG, Sony, Warner, Universal y EMI) y pronto se amplió a disqueras independientes. En 2004, el servicio entró al mercado europeo (IFPI, $2004,5)$ y en 2011, a Latinoamérica (IFPI, 2012, 8). Entre sus ventajas estaba que se podían escuchar 30 segundos de cada canción, antes de comprarse, y su calidad en el sonido era mejor que aquellos archivos que se intercambiaban gratuitamente [23], de manera que nuevamente se buscaba que los clientes concibieran que pagar por la música generaba un valor agregado, sobre los fonogramas adquiridos en sistemas ilegales P2P.

Igualmente, iTunes, como empresa privada y como aliada de la RIAA y de las disqueras, pudo mantener el control sobre la música, al integrárseles a los archivos de las canciones en MP3, mecanismos que solo permitían compartir el fonograma hasta en cinco computadores o dispositivos [24]. Esto también fue posible porque Steve Jobs creía firmemente en la protección de los derechos de autor de los artistas, quienes debían ganar dinero por la explotación de sus obras (Isaacson, 2011, 490).

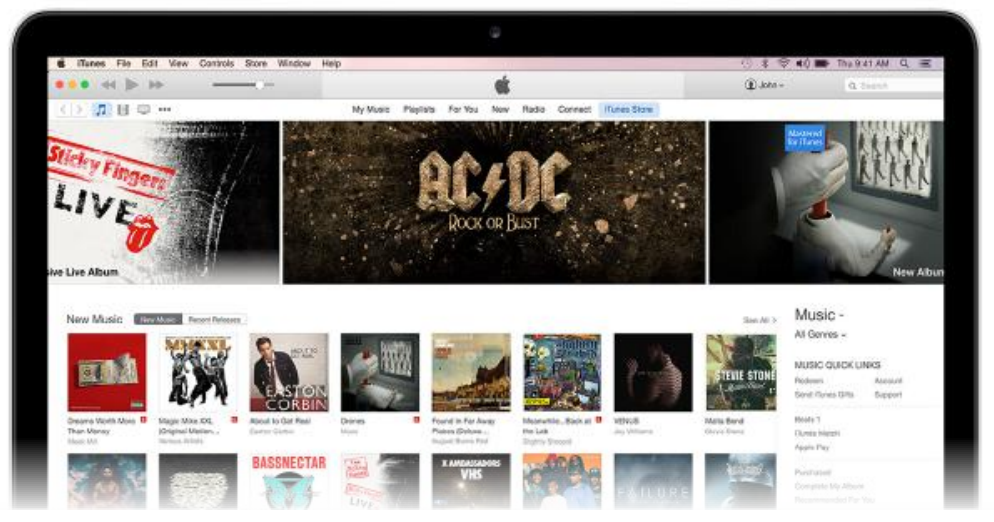

Con la invención de iTunes, la industria discográfica parecía frenar la piratería y volver a controlar el negocio de los fonogramas. Sin embargo, los sistemas ilegales P2P le hicieron la competencia a la plataforma de Apple y, apoyados por miles de consumidores melómanos, el MP3 continuó teniendo un carácter público, pese a los esfuerzos de Steve Jobs y las disqueras por lucrar sus corporaciones. Como resultado, cientos de portales para intercambiar música gratuita florecieron en la web y numerosos usuarios se conectaron para compartir sus archivos, que ahora consideraban de su propiedad. Por ejemplo, de 2001 a 2002, Kazaa aumentó de 9 a 64 millones de usuarios y Morpheus de 10 a 89 millones (Civano, 2003, 5)

El aumento de la piratería también llegó a niveles alarmantes para la industria discográfica cuando, a partir de 2008, los usuarios de los teléfonos inteligentes comenzaron a descargar la música en sus aparatos y a compartirlos a través de Bluetooth (Valencia, 2008, 12), lo cual dejó cada vez más claro que los consumidores percibían como un derecho el compartir las canciones que obtenían de Internet, sin tener en cuenta las leyes de propiedad intelectual. Como resultado, en 2011 , el $23,76 \%$ del tráfico de la web infringía el copyright, siendo BitTorrent, 
RapidShare y MegaUpload las más populares en el uso gratuito de archivos fonográficos (Luzardo, 3 de febrero de 2011).

A medida que transcurrían los años del nuevo milenio, la situación cada vez era peor para la industria discográfica, la cual fue incapaz de innovar sus modelos de negocio, mantener el nivel productivo de antaño, imponer sus gustos musicales a los usuarios (Hernández, 2011, 18) y ofrecer alternativas de pago en la web para mantener el uso privado y el carácter comercial del fonograma, ya que "the acceptance rate of paying for online content is extremely low" [25] Ching Lin, Chieh Hsu \& Ching Chen, 2013, 315). En 2005, dentro de las corporaciones del sector del entretenimiento, los sellos disqueros cedieron su lugar a Live Nation, una productora de conciertos con sede en California (Wikstrom, 2014) y en 2010, las disqueras apenas comercializaron 7.000 millones de dólares en Estados Unidos, siendo apenas la mitad de los ingresos de 1999 (Stanislas, Faulk \& Goodrich, 2013, 166).

Ante esta situación, la industria discográfica decidió combatir los servicios P2P, anotándose no pocos triunfos. Se partía de la lógica de que a menos plataformas piratas existiesen en la web, mayores las probabilidades de que los melómanos pagaran por los contenidos fonográficos en iTunes y otros negocios legales. De esta forma, los tribunales internacionales cerraron varios portales online que no tenían licencias para descargar música y así se clausuraron: Grokster en 2005, en Estados Unidos (Wallace, 2005, 154), OiNK en 2008, en Inglaterra (Hammond, 2014, 390), Qsound en 2009 en Latinoamérica (Preston \& Rogers, 12) y LimeWire en 2010 en Norteamérica (IFPI, 2012, 21).

De igual forma, durante el nuevo milenio, la industria discográfica también decidió perseguir a los usuarios que descargaban música ilegalmente, sin importar que realmente fueran comerciantes clandestinos que obtenían alguna remuneración económica por la comercialización de fonogramas de MP3 o consumidores que adquirían pocas canciones para su uso personal. El punto era contrarrestar la visión anti comercial de los internautas, quienes ya no sólo eran unos simples piratas, sino unos verdaderos convencidos de desprivatizar los bienes fonográficos para manipularlos a su antojo. Como resultado, las disqueras enviaron 20 millones de mensajes de advertencia a los cibernautas que violaban los derechos de autor, mayoritariamente en EE.UU, pero también en Europa, a partir de mediados de 2003 (IFPI, 2004, 14).
Estas notificaciones fueron el preámbulo a miles de demandas que la RIAA y las disqueras entablaron contra los consumidores de música. Si bien varias denuncias prosperaron a favor de la industria discográfica, la cual se anotó un éxito jurídico en la protección de la propiedad intelectual, los sellos dañaron su imagen de marca al actuar contra los internautas y con poca ética (Hougaard \& Tvede, 2010, 100; Easley, 2005, 166; Spotts, 2010, 79), al percibirse en la opinión pública que las majors estaban dispuestas a perjudicar a futuros clientes, con tal de insistir en su modelo de negocio de defensa extrema del derecho de autor.

En diciembre de 2008, la RIAA abandonó las demandas masivas a los internautas piratas (Arewa, $2010,446)$, pero las razones fueron más económicas que morales, ya que la industria discográfica gastaba una considerable suma de dinero en el litigio y en la investigación del infractor (Wallace, 2012, 155; Civano, 2003, 6). En cambio, el continúo intercambio de canciones entre miles de internautas favoreció el uso libre de la música, y se incrementaron las descargas de mp3. En términos generales, la opinión pública apoyó a los demandados y a los artistas (Venegas, 2009, 39), más no a las empresas que financiaban las producciones fonográficas y que, por lo general, eran dueñas de los derechos autor.

Este apoyo a los internautas que descargaban música sin pagar se vio reflejado en la creación de un partido pirata en Suecia, en 2006 (Yudice, 2007, 76), cuya ideología buscaba eliminar la propiedad intelectual y auspiciar el copyleft (del inglés izquierda en contraposición al copyright de derecha [26]), que era una fórmula, "en el ámbito del software libre [en que] el autor de un programa lo declara como dominio público" (Ramírez \& Gómez, 2011, 117) y puede modificarse, copiarse o distribuirse a disposición del consumidor (Kleiner, 2010, 36). Por ejemplo, bandas como Nine Inch Nails o Radiohead [27] pusieron en la web sus canciones sin ningún tipo de control por parte de las disqueras, y permitiendo que los usuarios obtuvieran libremente sus fonogramas, en un acto sin precedentes.

Por su parte, la industria discográfica en Estados Unidos reaccionó mediante el impulso de una normativa legislativa y actualizada para frenar la piratería a nivel nacional [28], y así mantener la defensa extrema del derecho de autor, en una época en que el acceso a la economía digital había democratizado el intercambio de los fonogramas, había puesto en tela de juicio el concepto de la privatización de productos 
intangibles e inmateriales (como el Mp3), y había cuestionado al capitalismo, que aboga por defender la propiedad intelectual desde el Congreso, órgano que tradicionalmente ha sido objeto de lobby por parte de las disqueras [29] (Welsh, 2009, 1509).

Los intereses comerciales y económicos de los sellos discográficos fueron defendidos en el senado y la cámara de representantes de Estados Unidos, a través de la ley SOPA (Stop Online Piracy Act) y PIPA (Protect IP Act), en 2012. Esta nueva legislación buscaba endurecer las penas contra usuarios que descargasen música, permitir a entidades de derechos de autor revisar los emails de los internautas en busca de material con copyright, y bloquear páginas web con contenido pirata sin orden de un juez. Sin embargo, las medidas fueron impopulares, por su carácter anti democrático de amenazar la libertad de expresión y, tanto el presidente Barack Obama como el congreso, rechazaron ambas propuestas por los términos tan polémicos como fueron redactadas [30].

Al tiempo que las disqueras se ocupaban de librar batallas jurídicas por la defensa del derecho de autor, la industria discográfica continuó viendo con preocupación la caída de sus ingresos y el particular rechazo que generaba entre los consumidores el tener que pagar por una copia de MP3 porque, al fin y al cabo, se podía duplicar instantáneamente en un computador con la misma calidad del original. La negativa de asumir los costos en la producción de un fonograma fue evidente en los usuarios más jóvenes quienes, culturalmente han vivido en un ambiente más digital y han coexistido en "an environment where old assumptions about how we treat information do not hold" (Mason, 2008, 4).

Los jóvenes son a quienes más les gusta adquirir música gratuita por Internet (Wallace, 2012, 145; Fox, 2002), compartir sus canciones favoritas en la web (Klein, 2010, 368) y son los más reacios a pagar por fonogramas [31] (Swanson, 2013, 214). Estas estadísticas hicieron pensar en nuevos modelos de negocio que motivaran a los adolescentes y a los estudiantes universitarios a invertir en álbumes y sencillos de una manera económica, digital e innovadora, de manera que se pensó en crear las plataformas de streaming o servicios en la nube que, al tiempo que generaban regalías para las disqueras y los artistas, satisfacían las nuevas necesidades de una población que no se había tenido en cuenta.

De esta forma, entre 2006 y 2015, aparecieron varias plataformas de streaming como Deezer,
Spotify [32], Apple Music, Tidal y Google Music que, generalmente, ofrecen el acceso desde diferentes dispositivos móviles (teléfonos inteligentes, tabletas), con sistemas iOS y Android; pagar la factura del servicio con la cuenta del celular, consultar listados y biografías de cantantes, crear listas de reproducción con las canciones favoritas del usuario y compartirlas a través de Facebook (López, 2014, 57), y aprovechar grandes catálogos que han sido facilitados por las majors y otras disqueras independientes, en su afán de mantener el ánimo de lucro de sus fonogramas, en portales que aprovechen la tecnología digital.

Los modelos de ingresos de estas plataformas de streaming son normalmente dos. Uno pago, con una tarifa que varía entre 8 y 15 dólares, dependiendo del país y del servicio, y cuyo dinero va para pagar las regalías de las disqueras y los artistas y, otro gratis, legal y donde el usuario debe oír propaganda y ver banners de publicidad, lo cual concilia la posición comercial de la industria discográfica, con la postura anti mercantil de los clientes, ya que ahora los contenidos fonográficos son libres y los portales son lícitos [33].

No obstante, los sellos discográficos y artistas, como la islandesa B Jork, [34] han presionado durante 2015 a las plataformas de streaming para eliminar la versión gratuita (financiada con propaganda), y así obligar a los usuarios a suscribirse a la opción Premium. En palabras de Patrik Wikstrom "los propietarios de los derechos insisten en que sus ingresos no pueden depender de los resultados que obtenga el equipo de ventas de publicidad del servicio y que este debe pagarles por la música que distribuya a sus clientes" $(2014,17)$.

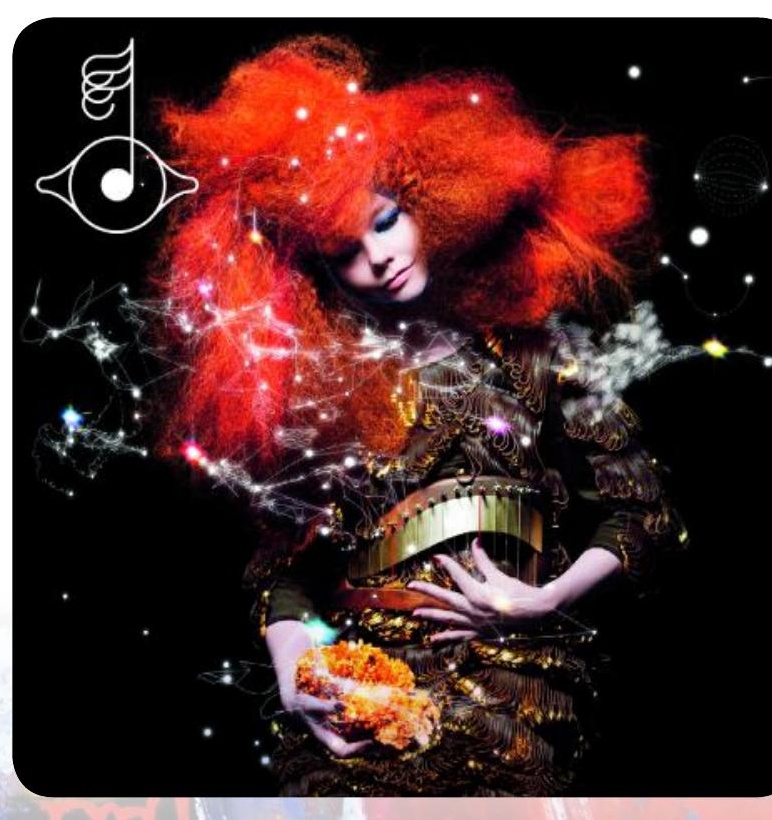


Esto indica que la industria discográfica estaría volviendo otra vez a la guerra de la defensa extrema del derecho de autor, a través de la concepción de la propiedad del fonograma, el control absoluto de los usuarios y del mayor lucro que se obtendría por servicios de suscripción. De manera que, "el reto para Spotify [35] y otros servicios freemium es conseguir equilibrar las diferentes versiones de modo que estimulen la conducta correcta en el consumidor y lo animen a convertirse en suscriptor de pago" (Wilkstrom, 2014, 6).

En la actualidad, esta lucha por mantener la supremacía por el control de la música se está mudando a las plataformas de streaming, donde, por un lado, las disqueras quieren hacer del fonograma un producto lucrativo, privado y comercial, mientras que los usuarios que disfrutan de los amplios catálogos de los servicios en la nube, desean escoger por su propia voluntad si pagan por un valor agregado o si continúan percibiendo el acceso a los contenidos musicales como libre, público y gratuito.

En suma, las tendencias están apuntando a reducir la rivalidad en el campo del entretenimiento en Internet, entre lo lucrativo y lo gratuito, ya que las disqueras han cedido en ofertar sus grandes bibliotecas de fonogramas en las plataformas de streaming $y$, aunque han protestado por el modelo de negocio basado en publicidad, hasta ahora ningún sello ha retirado la totalidad de sus catálogos de los portales. Por ejemplo, en Francia, en 2006, una encuesta a 150 negocios musicales, mostró que el $81 \%$ autorizaba a sus artistas a colocar muestras gratuitas de sus obras (Bourreau, 2013, 335), lo que años más tarde permitiría exponer colecciones completas sin costo.

Finalmente, los melómanos en Internet también han cedido en admitir que quien produce un álbum o un sencillo debe tener una remuneración económica. De manera que, con el modelo de negocio adecuado, es decir, con los servicios de streaming, los usuarios han vuelto a pagar por acceder a los contenidos fonográficos, los cuales son adquiridos por descargas lícitas de mp3, servicios en la nube y portales piratas. Esto se infiere de más de 16.000 encuestas en Europa, donde se les preguntó a los internautas la forma de consumir música y se concluyó que un mismo individuo podía crear una cuenta en Spotify, comprar canciones en iTunes y obtener archivos de mp3 de forma ilegal (Aguiar \& Martens, 2013, 23), situación que ha llevado a la industria discográfica a nuevos retos en cuanto al análisis del perfil del cliente.
CONCLUSIÓN

Como se ha visto a lo largo del texto, la percepción del fonograma ha estado marcada por dos nociones opuestas. Por un lado, el desarrollo de la industria discográfica ha basado su poder en el valor monetario de la música, la cual ha sido concebido por las disqueras como un bien privado, protegido por derechos de autor y, por tanto, comercializable. Por otra parte, la visión de los consumidores imaginó la adquisición de álbumes y sencillos como gratuita, libre y anti industrial, desde que en 1999, estuvieron disponibles miles de canciones sin pagar, en la plataforma de Napster en la web.

Desde finales de los noventa, Internet y la digitalización de fonogramas cuestionaron el modelo de negocio tradicional de comercializar discos físicos y plantearon una alternativa tanto para consumidores como para las empresas disqueras, ya que "la tecnología así como ha hecho que evolucione la industria discográfica facilitando su distribución y promoción así mismo se ha convertido en el arma de doble filo que de igual manera la ha perjudicado con la piratería" (Herrera, 2008, 51).

Esta disyuntiva se fue resolviendo, a lo largo del siglo, a favor de los consumidores, porque pese a que las disqueras apoyaron la creación de iTunes, además de lograr la clausura de Napster y otras plataformas similares, demandar a los usuarios de los servicios ilegales $\mathrm{P} 2 \mathrm{P}$ y financiar congresistas que defendieran los derechos de autor; en realidad, los melómanos que descargaban sus canciones favoritas de la Internet, cada vez se convencieron más del uso público del fonograma, aunque fueran llamados piratas por la industria discográfica por adquirir música sin pagarla.

Sin embargo, tanto usuarios como disqueras ganaron en esta lucha por el acceso a la música, lo cual confirma la hipótesis inicial de este artículo. Esto se evidencia a partir de 2006, cuando la industria discográfica lanzó los servicios de streaming, dándose la opción al usuario de escoger entre escuchar cientos de fonogramas gratuitamente con la condición de oír y ver la propagada que remuneraría los derechos de autor, o pagar una suscripción mensual por acceder a una biblioteca de miles de canciones sin publicidad.

Para confirmar la hipótesis, los melómanos ganaron porque continuaron con la opción -legal e ilegal- de descargar música y con la alternativa de acceder a las plataformas de streaming lícitas que ofrecen grandes catálogos de canciones gratis (con propaganda) y por pago (sin publicidad). También las disqueras 
salieron victoriosas con estos servicios en la nube porque, si bien están lejos de recuperar los ingresos de su época dorada de los noventa [36], se han mantenido en el negocio de la producción, promoción y distribución de fonogramas, pese a que formatos como los discos compactos han disminuido en sus ventas y los casetes prácticamente han desaparecido del mercado.

Esta situación ha llevado a considerar que la competencia de las disqueras en los servicios gratuitos y la cooperación entre usuarios en los sistemas $\mathrm{P} 2 \mathrm{P}$, al compartir sus canciones favoritas a través de la web, haya creado un nuevo modelo de negocio basado en la coopetencia [37], donde un sentido de comunidad online complementado con una sana rivalidad, mantendrá la armonía que se "traduce en mejores resultados para ambos" (Saldarriaga, 2011, 124), y así se dé lugar a un nuevo modelo de negocio.

También es evidente que partiendo de la hipótesis, en que tanto la industria discográfica como usuarios han ganado en su rivalidad por el acceso a la música, se han creado los modelos freemium, término del inglés entre "free" de libre o gratuito y "premium" de servicio con valor agregado, donde el fonograma en los servicios de streaming ahora es concebido como público, cuando el usuario no paga y tiene que escuchar la propaganda, pero con la opción de contar con acceso privado al suscribirse a una mensualidad para remunerar a las disqueras por los derechos de autor [38]

Estos modelos de ingreso freemium para las disqueras, además de temas de la sociología del consumidor musical en el nuevo milenio, el papel de los artistas en los nuevos negocios digitales y el impacto de YouTube en la industria discográfica, deben ser objeto de futuros trabajos por parte de la academia, ya que si bien ha habido una especie de tregua en la lucha por el acceso a la música entre sellos y usuarios, las plataformas de streaming podrían saturar de propaganda los servicios gratuitos para así presionar a los melómanos a pagar por los contenidos fonográficos y concebirlos nuevamente como bienes privados.

\section{BIBLIOGRAFIA}

AGUIAR, Luis; Martens, Bertin. (2013). "Digital music consumption on the internet: evidence from clickstream data". En: JRC Technical Reports: Digital economy working Paper 2013/04. Institute for prospective technological studies, Sevilla. Pp 1-40.

ALEXANDER, P.J. (2002). "Peer-to-peer file sharing: The case of the Music Recording Industry". En: Review of Industrial Organization. 20, 2. Pp 151- 161.

ARANGO, Fabián Eduardo (2015). "De lo offline a lo online: lo virtual como oportunidad de negocio de la Industria discográfica colombiana". En: Poliantea. Vol 10, No 19. Pp 95-144.

ARCOS Vargas, Andrea (2008). Industria musical en Colombia: una aproximación desde los artistas, las disqueras, los medios de comunicación y las organizaciones. Bogotá: tesis de la Pontificia Universidad Javeriana.

AREWA, Olufunmilayo B (2010). "YouTube, UGC, and Digital Music: Competing business and cultural models in the internet age". En: Northwestern University School of Law. Vol 104, No 2. Pp 431-475.

ARIAS, J.J; Ellis, Cameron (2013). "The decreasing excludability of digital music: implications for copyright law". En: Economist. 58, 2. Pp 124-132.

BALLEN Garzón, Cristian David (2011). Se fueron con su música a otra parte: los ensayaderos como nuevas formas de emergencia de artistas frente a la industria musical tradicional. Bogotá, Colombia: Tesis de la Pontificia Universidad Javeriana.

BARRIOS Rubio, Andrés (2011). De la onda web a la web. Paralelo entre la radio convencional y la radio virtual. Bogotá: Editorial de la Universidad Jorge Tadeo Lozano.

BETTS, Stephen C \& Taran, Zinaida (2004). "Getting their fair "share": the impact of disk copying on the music industry". En: Ethical and regulatory issues. Vol 8, No 1. Pp 35- 39.

BISHOP, Jack (2004). "Who are the pirates? The politics of piracy, poverty, and greed in a globalized music market”. En: Popular Music and Society. 27, 1. Pp 101-106. 
BOORSTIN, Eric (2004). Music sales in the age of file sharing. S.c: Princeton University, Department of Economics.

BOURREAU, Marc; Gensollen, Michel; Moreau, Francois, and Woelbroeck, Patrick (2013). "Selling less of more? The impact of digitization on record companies". En: J Cult Econ. 37. Pp 327-346.

BUQUET, Gustavo (2002). La industria discográfica: reflejo tardío y dependencia del mercado internacional. En: Bustamante Enrique. Barcelona: Editorial Gedisa.

CHING Lin, Tung; Chieh Hsu, Jack Shih, and Ching Chen, Hui (2013). "Customer willingness to pay for online music: the role of free mentality". En: Journal of Electronic Commerce Research. Vol 14, No 4. Pp 315-33.

CIVANO, Estela C (2003). La industria discográfica y la migración de valor. S.c: Universidad UBA. En: http://www.udesa.edu.ar/files/img/Administracion/45. PDF

COBO, Leila (15 de noviembre de 2008). En: Revista Billboard. Pag 6.

CRUM, Joshua (2008). "The Day the (Digital) Music Died: Bridgeport, Sampling Infringement, and a Proposed Middle Ground". En: Brigham Young University Law Review. 3. Pp 943-969.

SANDULLI, Francesco D y Barbero, Martín (2004). Música en internet: estrategias a seguir. En Universal Bussiness Review. Pp 30-41.

DAS, Sonia (2000). "The availability of the fair use defense in music piracy and internet technology". En: Federal communications law Journal. 52, 3. Pp 727747.

DINERO (2 de marzo de 2001). Napster sube el volumen. En: http://www.dinero.com/e-conomia/ edicion-impresa/articulo/napster-sube-volumen/9477

DINERO (27 de mayo de 2003). El debut de Apple. En: http://www.dinero.com/edicion-impresa/negocios/ articulo/el-debut-apple/4668

DINERO (12 de mayo de 2006). Sube el volumen. En: http://www.dinero.com/edicion-impresa/negocios/ articulo/sube-volumen/33254

DINERO (2 de febrero de 2012). Guerra digital. En: http://www. dinero.com/edicion-impresa/caratula/ articulo/guerra-digital/143793
DINERO (28 de noviembre de 2012). El ocaso de Prodiscos. En: http://www:dinero.com/empresas/ articulo/el-ocaso-prodiscos/165422

ENTER (4 de marzo de 2013). Google y Apple han hecho de la música algo sin valor. En: http://www. enter.co/cultura-digital/entretenimiento/google-yapple-han-hecho-de-la-musica-algo-sin-valor-thomyorke/

DURBIN, William Y (2007). "Recognizing the grey: toward a new view of the law governing digital music sampling informed by the first amendment". En: Williamm \& Mary Bill of Rigts Journal. 15. Pp 10211052.

EASLEY, Robert F (2005). "Ethical issues in the music industry response to innovation and piracy". En: Journal of Business Ethics. 62. Pp 163-8.

EL PAÍS de España (29 de agosto de 2005). Adiós a Rio, marca pionera de los reproductores http:// tecnologia.elpais.com/tecnologia/2005/08/29/ actualidad/1125304081_850215.html

EL TIEMPO de Colombia (17 de agosto de 1999). Acuerdo en mundo de sonido http://www.eltiempo. com/archivo/documento/MAM-937548

FAULK, Gregory K (2011). "The relation of prerecorded music media format and the U.S recording industry piracy claims: 1972-2009". En: Research in Business and Economics Journal, Belmont University. Vol 4. Pp $1-21$.

FLEET, Gabriel Jacob (2008). "What's in a song? Copyright's unfair treatment of record producers and side musicians". En: Vanderbilt Law Review. 61, 4. Pp 1235-1279.

FOUCE, Héctor (2010). "Tecnologías y medios de comunicación en la música digital: de la crisis del mercado discográfico a las nuevas prácticas de escucha". En: Revista Científica de Educomunicación. No 34, Vol 17. Pp 65-72.

FOX, Mark (Jun 2004). "E-Commerce business models for the music industry". En: Popular Music And Society. Vol 27, No 2. Pp 201-220.

FUCH, Christian (2008). Internet and society: social theory in the information age. New York: Taylor \& Francis Group.

GARCÍA Canclini, Néstor (2001). "Por qué legislar sobre industrias culturales". En: Nueva Sociedad. 175. Pp 60-69. 
GAROFALO, Reebee (1999). "From music publishing to MP3: music and industry in the twentieth century". En: American Music. 17, 3. Pp 318-353.

HAMMOND, Robert G (2014). "Profit Leak? PreRelease File Sharing and the Music Industry". En: Southern Economic Journal. 81, 2. Pp 387-408.

HARDAKER, Glenn \& Graham, Gary (2003). "Impact of on-line technologies for E-Music supplier networks". En: Journal of Services Research, Institute for International Management and Technology. Vol 3, No 1. Pp 6-27.

HERNÁNDEZ Escobar, Mayra Alejandra (2011). Manual de instrucciones. Autogestión y autopromoción musical en la web 2.0. Bogotá: tesis de la Pontificia Universidad Javeriana.

HERRERA, Andrés Camilo (2008). La importancia de la comunicación en la formación de marca para un artista de la música. Bogotá: tesis Universidad Javeriana, facultad de comunicación social.

HOLLANDER, Sam (2011). "Listen to the Music: Lessons for Publishers from Record Labels' Digital Debut Decade". En: Pub Res Q. 27. Pp 26-35.

HOUGAARD, Jens Let \& Tvede, Mich (2010). "Selling digital music: business models for public goods". En: Netnomics. 11. Pp 85-102.

IFPI (2004). Online Music Report. En: http://www. musikindustrie.de/fileadmin/news/ publikationen/pb_ digital-music-report-2004.pdf

IFPI (2012). Online Music Report. En: http://www.ifpi. org/content/library/dmr2012.pdf

ISAACSON, Walter (2011). Steve Jobs. Buenos Aires: editorial debate.

KASK, Johan (2011). "Evolving market channels in the swedish music industry: a dominant design approach". En: Segelod, Esbjorn (Ed). Studies in industrial renewal. Sweden: Malardaden University, Eskilstuna Vasteras.

KATZ, Mark (2009). Capturing sound: How technology has changed music. Los Ángeles: University of California Press.

KLEINER, Dmytri (2010). The telekommunist manifesto. Amsterdam: Institute of Network Cultures.

KASARAS, Kostas (7 de enero del 2002). Music in the age of free distribution: $\mathrm{mp} 3$ and society. En: First
Monday, vol 7, no 1. http://firstmonday.org/ojs/index. php/fm/article/view/927/849

LAING, Dave (1999). "The European music industry and European music policy". En: Cultural Trends, University of Westminster. 34. Pp 34-56.

LÓPEZ Lozano, Juana A. (2014). "El acceso a la información en la economía de red y su impacto en la industria discográfica". En: Revista Luciérnaga. 6, 11. Pp 52-62.

LUZARDO, Iván (3 de febrero de 2011). 24\% del tráfico de Internet es de contenido ilegal. En: Revista Enter. En: http://www.enter.co/otros/24-del-trafico-deinternet-es-de-contenido-ilegal/

MARTíNEZ Grau, Andrés (2008). Análisis de las estrategias de fidelización de clientes en las empresas Almacenes la Música y Prodiscos S.A. Tower Records de la ciudad de Bogotá, Bogotá: Tesis de pregrado de la universidad EAN.

MARTÍNEZ, Sebastián (16 de febrero de 2012). Grooveshark afronta un panorama cada vez más difícil. En: Revista Enter. En: http://www.enter.co/ chips-bits/apps-software/grooveshark-afronta-unpanorama-cada-vez-mas-dificil/

MASON, Matt (2008). Pirate's dilemma: how youth culture is reinventing capitalism. New York: Free Press.

MINISTERIO DE CULTURA (2003). Impacto económico de las industrias culturales en Colombia. Bogotá: convenio Andrés Bello.

MONROY Rodríguez, Juan Carlos (2006). "La industria musical colombiana en el mercado de los nuevos usos digitales". En: Revista La Propiedad Inmaterial. Universidad Externado de Colombia. 9. Pp 25-44.

MOREAU, Francois. (2013). "The Disruptive Nature of Digitization: The Case of the

Recorded Music Industry". En: International Journal Of Arts Management. 15, 2. Pp 18-31.

OCHOA, Ana María (2003). Músicas locales en tiempos de globalización. Bogotá: Norma.

PALMEIRO, César (2004). La industria discográfica y la revolución digital. Buenos Aires, Argentina: Facultad de ciencias económicas, Universidad de Buenos Aires. 
PAPAGIANNIDIS, Savvas \& Berry, Joanna (2007). "What has been learned from emergent music business models?". En: International Journal of E-Business Research. Vol 3, Issue 3. Pp 25-39.

GARCÍA Pérez, Jesús Francisco (2011). Propiedad intelectual: la información como bien público y bien privado. En: Morales Campos, Estela. Derecho a la información, bien público y bien privado: acceso comunitario y acceso individual. México: Universidad Nacional Autónoma de México.

PIKAS, Bohdan; Pikas, Anastacia \& Lymburner, Candice (2011). "The future of the music industry". En: Journal of Marketing Development and Competitiveness. Vol 5, No 3. Pp 139-149.

PORTAL, Carla Rosa, Barranquero, Luis Sánchez; García, María Torres (2013). La industria discográfica en España. En: Pérez Rufí, José Patricio. Industrias audiovisuales: producción y consumo en el siglo XXI. Málaga, España: Universidad de Málaga.

PRESTON, Paschal \& Rogers Jim (2011). "Social networks, legal innovations and the "new" music industry". En: Emerald Group Publishing Limited. Vol 13, No 6. Pp 8-19.

PUCCI Del Río, Pablo (2008). La crisis del disco: un análisis estratégico bajo la perspectiva del marketing. Chile: tesis de la Facultad de Economía y Negocios, Universidad de Chile.

RAMÍREZ, Sergio (Mayo/2003). Una historia pirateada. En: Revista Shock, Bogotá. Pp74-76.

RAMÍREZ, Julieta y Gómez, Nelson Eduardo (2011). Manual para el manejo de artistas musicales. Bogota: Impresiones Leograf.

RENARD, Stanislas; Faulk, Gregory \& Goodrich, Peter (2013). "Networks perspectives on

the relevance of new revenue streams in the digital era music industry". En: MEIEA Journal. Vol 13, No 1. Pp 149-79.

RIOT, Press (Mayo/2003). Se acerca el apocalipcd's. En: Revista Shock, Bogotá. Pp 72-74

ROGERS, Jim (2013). The death and life of the music industry in the digital age. S.c: Bloomsburry Academic.

ROJAS, Laura. (10 de junio de 2015). Spotify revela nuevas cifras. En: Revista Enter. En: http://www. enter.co/cultura-digital/entretenimiento/spotify-revelanuevas-cifras-paso-de-60-a-70-millones-de-usuarios/
Sebastián Saldarriaga (2011). Hágase rico por Internet. Bogotá: Intermedio Editores.

SCHNEIDER, James J (2012). "Defeating the terminator: how remastered albums may help record companies avoid copyright termination". En: Boston College Law Review. 53, 5. Pp 1889-1928.

SEMANA(15 de junio de 2015). ¿Qué hizo Taylor Swift para vencer a Apple?. En:_http://www.semana.com// tecnologia/articulo/taylor-swift-decidio-no-publicarsu-ultimo-album-en-el-streaming-de-apple/432317-3

SPOTTS, Harlan E (2010). "We'd rather fight than switch: music industry in a time of change". Journal of the International Academy for Case Studies. Vol 16, No 6. Pp 79-97.

STAHL, Matt; Meier, Leslie M (2012). "The Firm Foundation of Organizational Flexibility: The 360 Contract in the Digitalizing Music Industry". En: Canadian Journal of Communication. 37, 3. Pp 441458.

RENARD, Stanislas; Faulk, Gregory \& Goodrich, Peter (2013). "Networks perspectives on the relevance of new revenue streams in the digital era music industry". En: MEIEA Journal. Vol 13, No 1. Pp 149-79.

SWANSON, Kate (2013). "A case study on Spotify: exploring perceptions of the music streaming service". En: MEIEA Journal. Vol 13, No 1. Pp 207-230.

TSCHMUCK, Peter (2003). "How creative are the creative industries? A case of the music industry". Journal of Arts Management, Law, and Society. 33, 2. Pp 127-41.

THOMES Tim, Paul (2011). "An economic analysis of online streaming: how the music industry can generate revenues from cloud computing". En: Zew Discussion Papers. No 11-039. Pp 1-37.

VALENCIA Rincón, Juan Carlos (20 de junio de 2007). Cañonazos en Internet. En: http://www.semana.com/ entretenimiento/articulo/canonazos-internet/86671-3

VALENCIA, Jazmine A (2008). The Impact of Technology on the music industry. Boca Raton, Florida: Thesis in Florida Atlantic University.

VENEGAS, Eduardo (2009). Investigación de la industria musical y metodología en la producción de audio y construcción visual de una banda de rock. Bogotá: tesis de la Pontificia Universidad Javeriana, facultad de artes. 
WADE, Jared (2004). "The Music industry's war on piracy". En: Risk Management. 51, 2. Pp 10-15.

WALLACE, William (2012). "Authorizing piracy on the cyber seas: an initiative to compensate rights holders of sound recordings by making music free". 13, 42. Pp 141-172.

WEBER, Larry (2010). Marketing en las redes sociales (2 edición). México: ediciones Edamsa.

WELSH, Jared S (2009). "Pay what you like-No really: why copyright law should make digital music free for noncommercial uses". En: Emory Law Journal. 58, 6. Pp 1495-1535.

Wickstrom, Patric (2009). The music industry: music in the cloud. Cambridge: Polity Press.

YUDICE, George (2007). Nuevas tecnologías, música y experiencia. Barcelona: editorial Gedisa.

ZULETA, Luis Alberto y Jaramillo, Lino (2003). Impacto del sector fonográfico en la economía colombiana. Bogotá: edición del convenio Andrés Bello.

\section{NOTAS}

[1] La elaboración de este trabajo fue financiado por la Escuela de Administración de Negocios (EAN) de Bogotá, donde el grupo de investigación Cultura y Gestión, en su línea de Industrias Culturales, ha auspiciado la investigación interdisciplinaria de temas de música, innovación y tecnología.

[2] Según Jesús Francisco García "se define como bien privado aquel Bien que no puede ser consumido por más de una persona a la vez; cuando es consumido por una persona, todas las demás quedan excluidas de su consumo. Estos bienes son susceptibles de apropiación privada y tienen un precio en el mercado. Un bien público es un bien que, incluso si se consume por una persona, sigue disponible para el consumo de otras personas" $(2011,87)$.

[3] Según Héctor Fouce, las pocas investigaciones sobre el desarrollo y análisis de la industria discográfica en el nuevo milenio se deben a que "la velocidad de cambio hace que sean pocos los trabajos extensos sobre música digital, ya que los datos y las observaciones caducan si el proceso se dilata" (2010, 66).
[4] Copyright traduce en español derecho de autor. Su legislación data desde el acta de 1710 en Gran Bretaña y 1790 en Estados Unidos. Sin embargo, la protección de los trabajos musicales fue incluida en una nueva ley hasta 1831 en el Congreso norteamericano (Fleet, $2008,1261)$, agregándose la salvaguardia tanto a las composiciones en 1909, como a los sonidos de las grabaciones en 1971 (Schneider, 2012, 1895). De esta forma, la gestión durante la producción de un disco, empieza cuando el artista registra sus canciones llevando ante las entidades correspondientes la partitura y letra de las canciones (Ramírez \& Gómez, 2011, 150). Sin embargo, antes de los setentas muchos fonogramas aun no contaban con decretos que regularan su uso, y por tanto algunos cantantes como Harry Belafonte y duetos como Simon \& Garfunkel (con su tema el cóndor pasa), ganaron millones de dólares con canciones que no eran originalmente de ellos (García, 2001, 66).

[5] La guerra fría fue el conflicto ideológico, económico y político entre los Estados Unidos y la Unión Soviética entre 1945 y 1990. Mientras Moscú auspiciaba un sistema socialista con bienes estatales y públicos, Washington defendía el capitalismo y la propiedad privada. La música no escapó a esta rivalidad y mientras los consumidores -sin considerarse comunistas-, desearon un copyright menos restrictivo, las empresas americanas de los fonogramas, quisieron preservar el licenciamiento extremo de los derechos de autor. De allí a que autores que han estudiado la industria discográfica como Kostas Kasaras declarara que "in societies like ours the idea of property is thought as an unalienated human right that has to be protected; any action against it is ilegal" (2002). En: http://firstmonday. org/ojs/index.php/fm/article/view/927/849

[6] Las majors son grandes sellos discográficos que juntas han llegado a monopolizar la venta de fonogramas entre un 50 y $80 \%$ dependiendo del país. Estas son Universal, EMI, Sony, BMG y En palabras de Pucci Del Río, su objetivo "es la maximización de beneficios mediante la explotación comercial del artista" $(2008,39)$. Por el contrario, las indies, disqueras más pequeñas e independientes, "piensan que el éxito comercial no es lo más importante, aunque tampoco lo desprecian. Específicamente, destacan el aporte musical del artista y en un sentido más amplio, el cultural” (Pucci Del Río, 2008, 39). 
[7] Gregory K. Faulk muestra el continuo crecimiento de ingresos (en millones de dólares) de la industria discográfica estadounidense desde 1982 con $\$ 3.592$ a $\$ 14.584$ en 1999 , con la notable excepción de un leve declive en 1997 (2011, 16). Entretanto, el mercado colombiano de discos vivió un rápido ascenso entre 1992-97 (no hay datos desde antes). En 1991, se vendieron \$20,5, aumentando a 236,1 en 1997 (Zuleta \& Jaramillo, 2003, 51).

[8] En los primeros 150 años de existencia, los derechos de autor sólo fueron modificados dos veces en Estados Unidos: en 1831 (de 28 a 42 años) y en 1909 (de 42 a 56 años). En los sesentas se extendieron otros 50 años y en 1998 otras dos décadas (Bishop, 2005 , 454). En la actualidad, la propiedad intelectual de un fonograma hasta 70 años después de la muerte del artista (Bishop, 2005, 443-444).

[9] Por ejemplo, en Colombia, en 2003, un álbum de moda costaba entre 30.000 y 53.000 pesos, es decir un artículo de lujo para cualquier comprador de clase media y baja. (Riot, 2003, 73). Sobre el particular, Sergio Ramírez afirma: "tener que pagar entre 30.000 y 45.000 pesos por el último disco de Coldplay o Audioeslave parece no caer muy bien al bolsillo de cualquier estudiante medio, al que le toca bajarle a la cerveza o inventarse unas cuantas fotocopias para justificar el gasto ante sus acudientes" $(2003,75)$.

[10] En el caso particular de Colombia, una encuesta preguntó a la gente ¿Por qué no compró usted un CD en el 2000 ?, el $62 \%$ de los estratos bajos y el $45 \%$ de la clase media contestaron que porque ni siquiera tenían equipo de sonido donde reproducir los discos compactos (Ministerio de Cultura, 2003, 100).

[11] Leila Cobo, coincide con George Yudice en que los consumidores latinoamericanos no entienden el modelo de negocio impuesto por las disqueras, el cual no dimensiona sus necesidades económicas y culturales, y no tiene en cuenta otros factores como los altos precios de los fonogramas y los pocos avances en tecnología digital de la región (15 de noviembre de 2008, 6), donde los usuarios conciben la música como un bien público desde el nuevo milenio. Tal como dice Juana López: "en la medida en que la industria discográfica continúe con esa mirada obsesiva sobre la exclusividad y la venta de derechos, ésta se verá condenada al anquilosamiento" $(2014,58)$.

[12] En 2007, Sony-BMG tuvo que reembolsar dinero a sus clientes cuando estos alegaron que un software anti copia de discos compactos comprados legalmente había dañado su computador (Pucci Del Río, 2008, 35) Como puede verse, la industria discográfica trató de mantener también el control de la propiedad intelectual en los discos compactos tradicionales en plena época digital, sin lograr mayores resultados en su afán de controlar la producción de fonogramas.

[13] Igualmente, resultaron infructuosos la mayoría de arrestos a vendedores informales de discos que hizo la policía en diferentes partes del mundo para proteger los intereses económicos de las disqueras. Los consumidores melómanos se anotaron más éxitos en su lucha por la democratización de la música, pese a que la ley debía castigar a quienes la comerciaban ilegalmente, ya que en el caso de Colombia, las disqueras no pudieron esperar mayor cooperación ni de las autoridades policiales ni de las judiciales para solidificar su poder comercial, tal como lo evidencia el periodo entre 1997 y 1999, cuando se iniciaron procesos por delitos relacionados a la violación de derechos de autor contra 1000 personas, quienes en su mayoría terminaron sin detención (Zuleta \& Jaramillo, 2003, 126-127).

[14] Al dispositivo RIO podían conectársele audífonos (Das, 2000, 730) almacenaba hasta 60 minutos de música (Moreau, 2013, 24). También fue el antecesor de otros reproductores portátiles de MP3 como el Creative Labs', el Nomad, Pontis' y el Empeg's Empeg Car, al cual era posible introducírsele 5.000 canciones (Garofalo, 1999, 350).

[15] Para mayor información, puede verse la noticia en el diario El País de España (29 de agosto de 2005) http://tecnologia.elpais.com/tecnologia/2005/08/29/ actualidad/1125304081_850215.html y el periódico El Tiempo de Colombia (17 de agosto de 1999)

http://www.eltiempo.com/archivo/documento/MAM937548

[16] En Estados Unidos, en 1992, los discos compactos sobrepasaron en ventas a los casetes (Boorstin, 2004, 25), los cuales habían sido comercializados en EE.UU y Europa en gran cantidad en los años setentas y ochentas, mientras que en Latinoamérica (Zuleta \& Jaramillo, 2003, 25) y el resto del mundo sus ventas se dieron entre 1980 y 1998 (Laing, 1999, 38).

[17]Aunque el MP3 fue inventado en 1989 por el Instituto Fraunhofer de Alemania, y patentado en noviembre de 1996 en Estados Unidos, su comercialización masiva sólo fue posible hasta 1999 (Pikas \& Lymburner, 2011, 139), con la creación de Napster. 
[18]Aunque el MP3 fue inventado en 1989 por el Instituto Fraunhofer de Alemania, y patentado en noviembre de 1996 en Estados Unidos, su comercialización masiva sólo fue posible hasta 1999 (Pikas \& Lymburner, 2011, 139), con la creación de Napster.

[19] De esta misma opinión es Gerardo Galvis, gerente de Prodiscos en Colombia en 2012, quien le aseguro a la entrevistadora Daniela Blandon, que después de la piratería y la tecnología, la mayor preocupación de esta distribuidora de discos era que habían dos o tres generaciones que no sabían que era pagar por música. En: Revista Dinero (28 de noviembre de 2012), http://www.dinero.com/empresas/articulo/elocaso-prodiscos/165422. Mírese también este otro artículo en la misma magazine (12 de mayo de 2006) donde se aborda la gratuidad de los fonogramas en los usuarios más jóvenes http://www.dinero.com/edicionimpresa/negocios/articulo/sube-volumen/33254

[20] En 1996, se firmó en Estados Unidos el Digital Millenium Copyright Act (DMCA) (Wickstrom, 2009, 20) o Ley de Derechos de Autor del Milenio, la cual decía "un sitio no se hace responsable por el contenido pirata que enlacen o suban terceros" (Martínez, 15 de febrero de 2012). Sin embargo, los tribunales desecharon esta defensa en el caso de Grooveshark, porque los abogados demandantes de Universal encontraron que los empleados de la plataforma eran quienes habían subido miles de canciones al portal.

[21] En Estados Unidos los ingresos por venta de música habían disminuido (en millones de dólares) de $\$ 14.584$ en 1999 a $\$ 14.323$ en 2000 y a $\$ 13.740$ en 2001 (Faulk, 2011, 15).

[22] RealNetworks y PressPlay tuvieron todo tipo de inconvenientes en su uso debido al deseo de las majors a proteger desmesuradamente sus intereses privados y los derechos de autor. Entre sus defectos estuvo: su pesada interface, el límite de bajar los fonogramas en un solo computador, su prohibición a que las canciones fueran grabadas en un disco compacto o almacenadas en dispositivos de MP3 y el cobro de una suscripción por descarga de música, la cual se borraba si se el pago no se efectuaba. Revista Dinero (27 de mayo de 2003) En: http://www.dinero.com/edicion-impresa/ negocios/articulo/el-debut-apple/4668. La revista PC Word catalogó estos dos inventos como de los peores en la historia de la tecnología (Isaacson, 2011, 497498).
[23] Mírese la Revista Dinero del 2 de marzo de 2001. En: http://www.dinero.com/e-conomia/edicionimpresa/articulo/napster-sube-volumen/9477

[24] El 7 de abril del 2009, iTunes eliminó los mecanismos de protección de copiado de sus archivos de MP3 (Hollander, 2011, 34).Véase también la edición del 29 de enero de 2012 de la Revista Dinero para un resumen completo de la plataforma de Apple. http://www.dinero.com/negocios/articulo/subanvolumen/143120

[25] Por ejemplo, en Colombia, en una tesis expuesta por Andrés Martínez Grau, el autor concluyó que el $80 \%$ de los melómanos no pagaban por la música porque adquirirla era gratuita, un $14 \%$ por desconfianza en las transacciones y un $6 \%$ por carecer de tarjeta de crédito $(2008,28)$. De este trabajo de grado se infiere que efectivamente durante el nuevo milenio, el consumidor percibía un libre acceso a los fonogramas sin tener que pagar elevados costes por derechos de autor a las disqueras.

[26] Un caso particular donde se vieron estas dos fórmulas fue en 2004, cuando el cantante Danger Mouse grabó el Gray album, mediante la mezcla del Black album de Jay-Z, -quien autorizó la modificación de su obra musical- con el White album de The Beatles, cuya disquera EMI, dueña de los derechos de autor protestó por considerarlo como una violación a los derechos de autor (Durbin, 2007, 1022). Finalmente, la major desistió de presentar cargos contra el artista (Crum, 2008, 946).

[27] Radiohead dejó el álbum In Rainbows para su descarga gratuita por internet. Más tarde, su líder Thom Yorke ha lamentado que las empresas de streaming como Apple y Google han hecho de la música una mercancía. En Revista Enter (4 de marzo de 2013) http://www.enter.co/cultura-digital/entretenimiento/ google-y-apple-han-hecho-de-la-musica-algo-sinvalor-thom-yorke/. Igualmente, en 2002, Off Spring, banda de punk de California también había puesto sus canciones a libre disposición del público en internet, sin autorización de su disquera Sony (Alexander, 2002, 157).

[28] Radiohead dejó el álbum In Rainbows para su descarga gratuita por internet. Más tarde, su líder Thom Yorke ha lamentado que las empresas de streaming como Apple y Google han hecho de la música una mercancía. En Revista Enter (4 de marzo de 2013) http://www.enter.co/cultura-digital/entretenimiento/ 
google-y-apple-han-hecho-de-la-música-algo-sinIgualmente, en 2002, Off Spring, banda de punk de California también había puesto sus canciones a libre disposición del público en internet, sin autorización de su disquera Sony (Alexander, 2002, 157).

[29] En 2004, la industria discográfica en alianza con el sector cinematográfico hizo donaciones de más de 28.000.000 de dólares al Congreso para beneficiar las leyes del copyright. Entre los senadores más beneficiados estuvieron los Barbara Boxer y Dianna Feinstein, ambos de California, donde Hollywood tiene mucha influencia, además de los candidatos presidenciales, John Kerry (demócrata) y el entonces legislador John McCain (republicano) (Bishop, 2005, 457), dejando en claro que en posturas de propiedad intelectual ambos partidos políticos coinciden en sus posturas ideológicas de su defensa a los derechos de autor.

Mírese el artículo de Revista Dinero del 2 de febrero de 2012 en http://www.dinero.com/edicion-impresa/ caratula/articulo/guerra-digital/143793

[30] Mírese el artículo de Revista Dinero del 2 de febrero de 2012 en http://www.dinero.com/edicionimpresa/caratula/articulo/guerra-digital/143793

[31] Según la RIAA, en Estados Unidos, entre 1991 y 2000, el descenso en las ventas musicales por parte de los jóvenes cayó del 18.1 a $12.9 \%$ en los adolescentes entre $15-19$ años y de $17.9 \%$ a $12.9 \%$ entre los consumidores de 20-24 años, durante el mismo periodo. (Fox, 2004, 201). Por su parte, en Colombia, Gonzalo Olaya, jefe del departamento de publicidad y mercadeo de Prodiscos notó que quienes más entraban a estas tiendas tradicionales de disco eran los más adultos (citado por Martínez, 2008, 49).

[32] Spotify fue creado por Daniel Ek y Martin Lorentzon en Suecia en 2008. Un año más tarde las ganancias por streaming en este país fueron la mitad de aquellas generadas por descargas. En 2011, los servicios en las nubes dejaron 140.000.000 coronas en dividendos, más de tres veces que las plataformas P2P (Kask, 2011, 109).

[33] Sin embargo, la industria discográfica ha impuesto algunas limitaciones a los servicios que son libres o más económicos. Por ejemplo, la Sociedad de Autores y Compositores de Colombia (SAYCO), entidad encargada de recoger los derechos de autor de los artistas, prohíbe a las emisoras digitales permitir a los oyentes la descarga del podcast (Barrios, 2011, 86). [34] Véase el artículo de la revista Enter de Laura Rojas del 10 de marzo de 2015 http://www.enter.co/ chips-bits/apps-software/disqueras-pondrian-limitesa-version-gratis-de-servicios-de-streaming/

[35] Según Laura Rojas, desde finales de mayo de 2014 hasta junio de 2015, Spotify totalizaba más de 20 millones de usuarios suscritos y más de 75 millones de usuarios activos." (10 de junio de 2015). En: http:// www.enter.co/cultura-digital/entretenimiento/spotifyrevela-nuevas-cifras-paso-de-60-a-70-millones-deusuarios/. Sin embargo, la empresa sueca ha tenido dificultades en repartir las utilidades a los artistas, ya que la canción Poker face de Lady Gaga reportó una ganancia de apenas $\$ 167$ dólares por un millón de reproducciones (Thomes Tim, 2011, 5).

[36] Por ejemplo Taylor Swift "explicó que la retirada de Spotify se debió a que la empresa "no paga lo suficiente" (Revista Semana, 15 de junio). En: http:// www.semana.com//tecnologia/articulo/taylor-swiftdecidio-no-publicar-su-ultimo-album-en-el-streamingde-apple/432317-3

[37] Este concepto es definido por Sebastián Saldarriaga como "un nuevo término en los negocios por internet, significa que es mejor ayudarse mutuamente a crear y crecer un mercado, que ponerse a competir" (2011, 124).

[38] Otros autores han inferido que el futuro de la industria discográfica está en conceder ayudas y subsidios por parte del Estado a las empresas musicales (Buquet, 2002, 92; Arias \& Ellis, 2013, 130); crear organismos internacionales que compensen a los artistas por sus obras (Wallace, 2012, 143) y en que las disqueras sobrevivan extendiendo sus negocios a la organización de conciertos y venta de mercancía de sus estrellas (Stahl \& Meier, 2012, 442).

\section{Para citar este artículo:}

ARANGO Archila, Fabián Eduardo (2015). LA INDUSTRIA DISCOGRÁFICA Y LOS CONSUMIDORES: ¿La música como bien comercial o gratuito? Revista Luciérnaga/ Comunicación, Año 7, N13. Facultad de Comunicación Audiovisual- Politécnico Colombiano Jaime Isaza Cadavid-PCJIC \& Facultad de Ciencias de la Comunicación - Universidad Autónoma de San Luis Potosí- UASLP. México. ISSN 2027- 1557. Págs. 13-31. 